\title{
A study of maternal awareness of acute diarrhoeal disease
}

\author{
A L P de S Seneviratne ${ }^{1}$ \\ Sri Lanka Journal of Child Health, 2003; 32: 66-8
}

(Key words: Maternal awareness, acute diarrhoeal disease, children)

\begin{abstract}
Objective To determine maternal awareness regarding acute diarrhoeal disease and use of oral rehydration solution (ORS).

Method Study was carried out in a suburban family practice on mothers/carers of children, presenting with acute diarrhoea, using an interview-based questionnaire to collect data. Mother's/Carer's knowledge regarding causes and transmission of diarrhoea, use of ORS and its method of preparation, were assessed.
\end{abstract}

Results Knowledge about causative factors and transmission of acute diarrhoea among mothers/carers was poor. Though aware of ORS, a majority prepared it incorrectly.

\section{Introduction}

Diarrhoeal disease is a global health problem and is estimated to cause about 4.6 million deaths per year, in children below 5 years of age, in developing countries ${ }^{1}$. A major obstacle to control and prevention of diarrhoea and dehydration in children may be lack of maternal knowledge about diarrhoea and use of oral rehydration solution (ORS). Oral rehydration is now an accepted therapy for prevention and treatment of dehydration resulting from diarrhoea and vomiting. In this study, maternal awareness of transmission of acute diarrhoea and use of ORS is analysed.

\section{Method}

Study was carried out in a family practice clinic at Ratmalana over a period of 24 months. A pre-tested interview based questionnaire was used. The study sample included mothers/carers of children below 15 years of age presenting with acute diarrhoea. As study was designed to test mother's knowledge and practices regarding acute diarrhoea, children seen only once during this period, were excluded. Following data were recorded - age and sex of children, educational level of

\footnotetext{
${ }^{1}$ Senior Lecturer in Family Medicine, University of Sri Jayawardenapura, Nugegoda.
}

(Received on 10th July 2003) mothers/carers, their knowledge on causes and transmission of diarrhoea, awareness on ORS and its preparation.

\section{Results}

There were 377 children in study sample of whom 215 were boys. Age distribution of children presenting with acute diarrhoea is shown in Table 1.

Table 1

Age distribution

\begin{tabular}{|l|c|}
\hline \multicolumn{1}{|c|}{ Age } & Number (\%) \\
\hline $0-6$ months & $47(12.5)$ \\
\hline$>6$ mths-2 years & $144(38.0)$ \\
\hline$>2-5$ years & $81(21.5)$ \\
\hline$>5-12$ years & $82(21.8)$ \\
\hline$>12-15$ years & $23(06.2)$ \\
\hline Total & $\mathbf{3 7 7}(\mathbf{1 0 0 . 0})$ \\
\hline
\end{tabular}

$272(72 \%)$ children were under the age of 5 years. Educational level of mothers/carers is shown in Table 2.

Table 2

Level of education of Mothers/Carers

\begin{tabular}{|l|c|}
\hline \multicolumn{1}{|c|}{ Education } & Number $(\%)$ \\
\hline No Schooling & $04(1.1)$ \\
\hline Below Primary & $16(4.5)$ \\
\hline Grade 5-9 & $63(17.8)$ \\
\hline G.C.E.O/L & $153(43.0)$ \\
\hline G.C.E.A/L & $100(28.0)$ \\
\hline Degree or Equivalent & $20(5.6)$ \\
\hline Total & $\mathbf{3 5 6 ( 1 0 0 . 0 )}$ \\
\hline
\end{tabular}

94.4\% were educated up to grade 5 and above. $76.6 \%$ had obtained General Certificate of Education, Ordinary level (GCE O/L), General Certificate of Education, Advanced level (GCE A/L) or higher qualifications. Mothers/Carers of 21 children did not give a proper answer regarding their educational standard.

Among the study population, 93\% were mothers while the rest were carers comprising aunts, grand mothers and other relatives. Beliefs of mothers/carers regarding cause of diarrhoea are shown in Table 3. 
Table 3

Beliefs regarding cause of diarrhoea

\begin{tabular}{|l|c|}
\hline \multicolumn{1}{|c|}{ Cause } & Number (\%) \\
\hline Wrong type of food & $155(44.4)$ \\
\hline $\begin{array}{l}\text { Eating food other than } \\
\text { from home }\end{array}$ & $41(10.5)$ \\
\hline Overeating & $03(0.5)$ \\
\hline Starting new food item & $07(2.0)$ \\
\hline Spoilt food & $07(2.0)$ \\
\hline Change of milk & $11(3.0)$ \\
\hline Worms & $14(3.5)$ \\
\hline Teething & $10(2.5)$ \\
\hline Super natural forces & $06(1.5)$ \\
\hline Germs & $51(13.5)$ \\
\hline Do not know & $64(14.5)$ \\
\hline Non responders & $08(2.1)$ \\
\hline Total & $\mathbf{3 7 7 ( 1 0 0 . 0 )}$ \\
\hline
\end{tabular}

Only 51(13.5\%) mothers/carers knew that diarrhoea was due to an infective organism. 8 mothers/ carers did not respond to this question. The 51 mothers/carers, who knew that the cause was due to infective organisms, had their educational standards above the GCE O/L. $90 \%$ of them knew that transmission was due to bad personal hygiene and/or contamination of food and water.

Mothers/Carers were questioned on awareness of ORS, its use and preparation. $361(96.5 \%)$ were aware of ORS. Only $13(3.5 \%)$ had not heard about ORS before. The main source of information regarding ORS is shown in Table 4.

Table 4

Main source of information regarding ORS

\begin{tabular}{|l|c|}
\hline Source of information & Number (\%) \\
\hline Electronic media & $138(38.2)$ \\
\hline Midwife/health worker & $04(1.1)$ \\
\hline MOH Clinic & $13(3.6)$ \\
\hline Hospitals & $43(11.9)$ \\
\hline G.P./F.P. & $158(43.7)$ \\
\hline Others & $05(1.5)$ \\
\hline Total & $\mathbf{3 6 1}(\mathbf{1 0 0 . 0})$ \\
\hline
\end{tabular}

$158(43.7 \%)$ mothers/carers who were aware of ORS had stated that General Practitioners/Family Physicians were the main source of information. 138 $(38.2 \%)$ gained information from electronic media, radio and television. 'Others' in this table include neighbours, friends and relatives. 16 did not respond. The main source of the ORS packets to mothers/ carers is shown in Table 5.
Table 5

Main source of ORS to mothers/carers

\begin{tabular}{|l|c|}
\hline \multicolumn{1}{|c|}{ Source } & Number (\%) \\
\hline Pharmacy & $215(59.6)$ \\
\hline Midwife/health worker & $03(0.8)$ \\
\hline MOH Clinic & $03(0.8)$ \\
\hline Hospital & $35(9.8)$ \\
\hline General Practitioner & $104(28.8)$ \\
\hline Others & $01(0.2)$ \\
\hline Total & $\mathbf{3 6 1 ( 1 0 0 . 0 )}$ \\
\hline
\end{tabular}

$59.6 \%$ had obtained the ORS packets from a nearby pharmacy and $28.8 \%$ from a General Practitioner.

226 mothers/carers said that they had prepared ORS recently and were questioned regarding the preparation and use of ORS. Following were taken as errors.

- Preparation of concentrated or diluted ORS by dissolving part/entire packet in a quantity of water less/more than 1 litre.

- Once prepared, using it, even after keeping it for $>24$ hours at room temperature.

Almost $50 \%$ of mothers/carers had prepared ORS incorrectly. Table 6 shows the comparison of their educational level with errors in preparing ORS.

Table 6

Comparison of ORS preparation and

Mother's/Carer's educational level

\begin{tabular}{|l|c|c|}
\hline $\begin{array}{c}\text { Educational } \\
\text { level }\end{array}$ & $\begin{array}{c}\text { No. Prepared } \\
\text { Correctly (\%) }\end{array}$ & $\begin{array}{c}\text { No. Prepared } \\
\text { Incorrectly (\%) }\end{array}$ \\
\hline No schooling & $00(0)$ & $02(100.0)$ \\
\hline Below primary & $01(10.7)$ & $12(92.3)$ \\
\hline Grade 5 - 9 & $20(37.1)$ & $34(62.9)$ \\
\hline G.C.E.O/L & $60(63.2)$ & $35(36.8)$ \\
\hline G.C.E. A/L & $25(55.6)$ & $20(44.4)$ \\
\hline Degree & $05(62.5)$ & $03(37.5)$ \\
\hline No response & $02(16.7)$ & $10(83.3)$ \\
\hline Total & $\mathbf{1 1 3 ( 1 0 0 . 0 )}$ & $\mathbf{1 1 6 ( 1 0 0 . 0 )}$ \\
\hline
\end{tabular}

Out of the 111 who had prepared ORS correctly, 90 $(81 \%)$ had studied up to GCE O/L and above. On the other hand, out of 106 who had prepared ORS incorrectly $58(54 \%)$ had studied up to the same grade. 


\section{Discussion}

In this study $155(41 \%)$ mothers/carers thought that diarrhoea was due to a wrong type of food given to child e.g. cheese, butter, fruits etc. Only 51(14.6\%) knew that it was due to an infective agent entering the gut. Over 50\% mothers/carers considered teething a cause of diarrhoea and a substantial number regarded crawling, worm infestation and eating food that is difficult to digest as factors causing diarrhoea. Wijewardene et $a l^{1}$ in a study done in 1989 within Galle municipality limits, showed that $61.9 \%$ mothers knew that diarrhoea was due to an organism entering body with contaminated water or food. Konde $e t a l^{2}$, in a nationwide study in Uganda, noted that dirty food $(50 \%)$, worms $(13 \%)$, teething $(9 \%)$, and dirty water $(5 \%)$ were the main causative factors for diarrhoea.

Of mothers/carers who had prepared ORS previously, $50 \%$ had prepared it incorrectly. Jeevani was the oral rehydration salt used by majority of mothers/carers. A study by Aloysius and Walgampaya ${ }^{3}$ showed that $39 \%$ had prepared ORS incorrectly even though $94 \%$ of them were educated up to grade 6 and above. A household case management study in Colombo municipality limits ${ }^{4}$ in 1990 , showed that $29 \%$ had prepared ORS incorrectly. In this study 96.5\% mothers were aware of ORS although $50 \%$ had prepared it incorrectly.

The main source of information regarding ORS was General Practitioners/Family Physicians (43.7\%) and the electronic media $(38.2 \%)$. It is clear that more publicity should be given to the correct method of preparing ORS. Incorrect preparation of ORS may be due to inadequacies in the instruction leaflet in Jeevani, which should be made more readable and clear. Measurement of a litre of water with household available bottles should be clearly explained to the mothers/carers. Findings in my study are consistent with those of Wijewardene el al in Galle ${ }^{1}$, De Silva in Padukka ${ }^{5}$, Sri Lanka and of Bhatnagar and Dosajh in Delhi ${ }^{6}$.

\section{Conclusions and Recommendations}

The study shows that mother's/carer's knowledge of transmission of diarrhoea and preparations of ORS was poor. The results indicate that the study population was aware of ORS through the electronic media and their family physicians. It will be important to educate the public that acute diarrhoea is caused by an infective organism entering via oral route, due to contamination of food or water. The family doctor should demonstrate the preparation of ORS in their clinics. Family doctors should take the main role in giving health education to the public through the electronic media.

\section{References}

1. Wijewardena K, Fonseka P, Wijesinghe W W A. Risk factors contributing to acute diarrhoeal disease. Ceylon Medical Joumal1992; 37:134-6.

2. Konde J. Knowledge, attitudes and practices and their policy implications in childhood diarrhoeas in Uganda. Journal of Diarrhoeal Disease Research 1992; 10(1): 25-30.

3. Aloysius D J, Walgampaya G. Preparation of oral rehydration solution and its attendant errors in family practice. Ceylon Journal of Child Health 1993; 22(1): 19-21.

4. Annual Health Bulletin in Sri Lanka 1990. CDD morbidity and mortality survey. 134-6.

5. De Silva A V K V. Research abstract South Asian Region, World Health Organization Regional Publication. 1990; 29:11.

6. Bhatnagar S, Dosajh U. Diarrhoeal disease morbidity in children below 5 years in urban slums of Delhi. Indian Journal of Medicine 1984; 7: 53-8. 
